\title{
CURRENT SENSITIVITY PATTERN OF MRSA (METHICILLIN RESISTANT STAPH AUREUS) IN A TERTIARY CARE ORTHOPAEDIC HOSPITAL IN KASHMIR (J\&K)
}

\author{
Shaika Farooq1, Altaf Ahmad Kawoosa2, Mohammad Umer Mumtaz ${ }^{3}$ \\ ${ }^{1}$ Assistant Professor, Department of Microbiology, Government Medical College, Srinagar. \\ ${ }_{2}^{2}$ Associate Professor, Department of Orthopaedics, Government Medical College, Srinagar. \\ ${ }^{3}$ Assistant Professor, Department of Orthopaedics, Government Medical College, Srinagar.
}

\begin{abstract}
In view of the reported emergence of vancomycin resistance in MRSA from the state and the country as a whole we evaluated the pattern of culture and sensitivity on 160 samples from Orthopaedic Department over a period of one year between Nov 2014 and Nov 2015. These belonged to 111 males and 49 females with different aetiologies. Using standard protocols for the culture, 84 (52\%) samples grew no organisms while Staph aureus was grown in 43 samples (26.8\%) and gram negative organism in 28 and 5 samples grew mixed organism. Out of these 43 isolates of Staph aureus, MRSA was grown in 32 (74.4\%) and MSSA in 11 (25.6\%). These belonged to $23(71.8 \%)$ males and $9(28.1 \%)$ females. Majority of MRSA were grown from the patients of acute osteomyelitis and operated fractures (63.3\%). Linezolid showed highest sensitivity (100\%) followed by Vancomycin (96.8\%), Clindamycin (37.5\%), erythromycin (21\%), Amikacin (21\%), Levofloxacin (9.3\%), cotrimoxazole (9.3\%) and ciprofloxacin (3.1\%). By diffusion method 6 positive cultures depicted doubtful sensitivity pattern for vancomycin (18.75\%). However, on further analysis using MIC only one isolate (3.3\%) showed intermediate resistance to vancomycin; 12 cultures (37.5\%) were sensitive to vancomycin and linezolid only. The presence of vancomycin resistance calls for a watchful approach towards these infections and an extensive study to better define the problem.
\end{abstract}

\section{KEYWORDS}

MRSA, Vancomycin Resistance.

HOW TO CITE THIS ARTICLE: Farooq S, Kawoosa AA, Mumtaz MU. Current sensitivity pattern of MRSA (methicillin resistant staph aureus) in a tertiary care orthopaedic hospital in Kashmir (J\&K). J. Evolution Med. Dent. Sci. 2016;5(12):503-505, DOI: $10.14260 /$ jemds/2016/115

\section{INTRODUCTION}

Staph aureus is the commonest organism responsible for orthopaedic infections and its prevalence has been on rise in India. ${ }^{1}$ The overall infection rate following internal fixation is approximately 5\%. ${ }^{2}$ MRSA (Methicillin Resistant Staph Aureus) induced biofilms are responsible for implant infections and these biofilms are up to 100 times more resistant to antibiotics including Vancomycin. ${ }^{3}$ The emergence of Methicillin resistance described in 1961 has made the management in these infections even more difficult as these organisms are resistant to all available penicillins and other Beta-lactam antimicrobial drugs. Penicillin Binding Protein (PBP2a) responsible for this resistance is encoded on the methicillin-resistance gene, mecA. ${ }^{4}$ To add to the problems there are reports of emergence of Vancomycin resistance in S. aureus from India.5,6,7 with this background the present study was undertaken to assess the current sensitivity pattern of MRSA in our Orthopaedic Department to define the judicious use of antibiotics against them.

\section{MATERIALS AND METHODS}

We analysed the culture and sensitivity pattern of samples received from the Orthopaedic Department of our institution for various aetiologies for a period of one year between Nov 2014 and Nov 2015.

Financial or Other, Competing Interest: None.

Submission 25-12-2015, Peer Review 19-01-2016,

Acceptance 27-01-2016, Published 09-02-2016.

Corresponding Author:

Dr. Shaika Farooq,

Assistant Professor, Department of Microbiology,

Govt. Medical College, Srinagar.

E-mail: drshaika1farooq@yahoo.com

DOI: $10.14260 /$ jemds/2016/115
The study included a total of 160 samples that belonged to 49 females and 111 male patients in an age group of 1 to 75 years (Average 38 years). The study and was conducted in the Department of Microbiology, GMC Srinagar. The samples consisted of pus cultures from the cases of osteomyelitis, the surgical wounds, open fractures, joint aspirates and infected implants (Table 1). These 160 non-duplicate pus samples were processed for routine bacteriological culture as per the standard protocol. ${ }^{8}$ Isolates were identified using standard biochemical techniques and then subjected to susceptibility testing by Kirby Bauer's disc diffusion method on Mueller Hinton agar plates. The Staphylococcus aureus isolates were tested using penicillin $(10 \mathrm{U})$, cefoxitin $(30 \mu \mathrm{g})$, erythromycin $(15 \mathrm{~g})$, cotrimoxazole $(1.25 \mu \mathrm{g} / 23.75 \mu \mathrm{g})$, clindamycin $(2 \mu \mathrm{g})$ gentamicin $(10 \mu \mathrm{g})$, ciprofloxacin $(5 \mu \mathrm{g})$, amikacin $(10 \mu \mathrm{g})$ Vancomycin $(30 \mu \mathrm{g})$ and Linezolid $(30 \mu \mathrm{g})$ discs and incubated at $35^{\circ} \mathrm{c}$ in ambient air. ${ }^{9}$ Cefoxitin disc was used as surrogate marker for oxacillin resistance.

All Isolates were identified as Penicillin resistant or sensitive on the basis of diameter of zone of inhibition around antibiotic discs as per CLSI guidelines. Penicillin sensitive staphylococci (Zone diameter $>$ or $=29 \mathrm{~mm}$ ) were further screened for $\beta$ lactamase production by penicillin zone edge test. Any sharp zone edge (Cliff) was taken as $\beta$ lactamase positive and fuzzy zone edge (Beach) was taken as $\beta$ lactamase negative. On the basis of cefoxitin disc diffusion isolates were further categorised into Methicillin sensitive (Zone diameter >or $=22 \mathrm{~mm}$; mecA negative) and methicillin resistant (Zone diameter $<$ or $=21 \mathrm{~mm}$; mecA positive) Staph aureus. MRSA strains with doubtful sensitivity to vancomycin were further subjected to Vitek 2 compact system. 


\begin{tabular}{|c|c|c|c|}
\hline Sl. No. & Aetiology & No. of Samples & \% \\
\hline 1 & Acute osteomyelitis & 39 & 24.3 \\
\hline 2 & Operated fractures & 40 & 25 \\
\hline 3 & Chronic osteomyelitis & 17 & 10.6 \\
\hline 4 & Septic arthritis & 15 & 9.3 \\
\hline 5 & Infected implants & 12 & 7.5 \\
\hline 6 & Surgical site infection & 9 & 5.6 \\
\hline 7 & Tumours & 5 & 3.1 \\
\hline 8 & Abscess & 5 & 3.1 \\
\hline 9 & Miscellaneous & 18 & 11.2 \\
\hline \multicolumn{4}{|c|}{ Table 1: Distribution of samples } \\
\hline
\end{tabular}

\section{RESULTS}

After 24 hrs. incubation and assessment 84 (52\%) samples grew no organisms, while as Staph aureus was grown in 43 samples $(26.8 \%)$ and gram negative organisms in 28 , while 5 samples grew mixed organisms (Table 2).

\begin{tabular}{|c|c|c|c|}
\hline Sl. No. & Organism Grown & No. & \% \\
\hline 1 & No growth & 84 & 52 \\
\hline 2 & MRSA & 32 & 20 \\
\hline 3 & MSSA & 11 & 6.8 \\
\hline 4 & E. Coli & 12 & 7.5 \\
\hline 5 & Pseudomonas & 6 & 3.7 \\
\hline 6 & Klebsiella & 4 & 2.5 \\
\hline 7 & Citrobacter & 3 & 1.8 \\
\hline 8 & Proteus & 1 & 0.6 \\
\hline 9 & Acinobacter & 1 & 0.6 \\
\hline 10 & Enterococcus & 1 & 0.6 \\
\hline 11 & Mixed & 5 & 3.1 \\
\hline \multicolumn{4}{|c|}{ Table 2: Distribution of organism grown } \\
\hline
\end{tabular}

Out of these 43 isolates of Staph aureus, MRSA was grown in $32(74.4 \%)$ and MSSA in (25.6\%). These belonged to $23(71.8 \%)$ males and $9(28.1 \%)$ females. (Table 3) Majority of MRSA were grown from the patients of acute osteomyelitis and operated fractures (63.3\%).

\begin{tabular}{|c|c|c|c|c|}
\hline $\begin{array}{c}\text { Sl. } \\
\text { No. }\end{array}$ & Aetiology & $\begin{array}{c}\text { No. of } \\
\text { Samples }\end{array}$ & $\begin{array}{c}\text { Positive } \\
\text { Cultures } \\
\text { for MRSA }\end{array}$ & $\begin{array}{c}\text { \% } \\
\text { Positive } \\
\text { Cultures }\end{array}$ \\
\hline 1 & $\begin{array}{c}\text { Acute } \\
\text { Osteomyelitis }\end{array}$ & 39 & 13 & 33.3 \\
\hline 2 & $\begin{array}{c}\text { Operated } \\
\text { Fractures }\end{array}$ & 40 & 12 & 30 \\
\hline 3 & $\begin{array}{c}\text { Septic } \\
\text { arthritis }\end{array}$ & 15 & 2 & 13.3 \\
\hline 4 & Abscess & 05 & 2 & 40 \\
\hline 5 & $\begin{array}{c}\text { Surgical site } \\
\text { infection }\end{array}$ & 12 & 2 & 16 \\
\hline 6 & $\begin{array}{c}\text { Infected } \\
\text { implant }\end{array}$ & 9 & 1 & 11 \\
\hline \multicolumn{5}{|c|}{ Table 3: Distribution of MRSA isolates } \\
\hline
\end{tabular}

\section{Sensitivity Pattern}

Linezolid showed highest sensitivity (100\%) followed by Vancomycin (96.8\%), Clindamycin (37.5\%), erythromycin (21\%), Amikacin (21\%) Levofloxacin (9.3\%), Cotrimoxazole (9.3\%) and ciprofloxacin (3.1\%) (Table 4). However, by diffusion method 6 positive cultures depicted doubtful sensitivity pattern for vancomycin (18.75\%). These were further analysed using MIC and only one isolate showed intermediate resistance to vancomycin (VISA). Twelve cultures $(37.5 \%)$ were sensitive to vancomycin and linezolid only.

\begin{tabular}{|c|c|c|c|}
\hline Sl. No. & Sensitive antibiotic & No. & $\mathbf{\%}$ \\
\hline 1 & Linezolid & 32 & 100 \\
\hline 2 & Vancomycin & 31 & 96.8 \\
\hline 3 & Amikacin & 07 & 21.8 \\
\hline 4 & Clindamycin & 12 & 37.5 \\
\hline 5 & Levofloxacin & 03 & 9.3 \\
\hline 6 & Ciprofloxacin & 01 & 3.1 \\
\hline 7 & Erythromycin & 07 & 21.8 \\
\hline 8 & Cotrimoxazole & 03 & 9.3 \\
\hline \multicolumn{4}{|c|}{ Table 4: Sensitivity pattern of MRSA to different drugs } \\
\hline
\end{tabular}

\section{DISCUSSION}

Out of the total non-duplicate, 160 samples of Staph aureus was grown in 43 samples (26.8\%), out of which 32 (74.4\%) were MRSA and one (3.3\%) showed intermediate resistance to vancomycin. By diffusion method, $37.5 \%$ were depicted as doubtful for vancomycin resistance, which however on evaluation of MIC reduced to only 3.3\%. Therefore caution should be exercised before labelling vancomycin resistance on disc diffusion method. The vancomycin resistance in present series closely matches previous report from the state. ${ }^{7}$ In a series of 120 strains of MRSA Assadaullah et al. found VISA in $3.3 \%$. However, the source of these strains has not been mentioned in their series, whereas the current study included isolates exclusively from a single speciality. Shiddanna M. ${ }^{10}$ et al. in their series of 131 orthopaedic specimens isolated Staph. Aureus in 38 (29\%) specimens of which 24 (63\%) were MRSA and $6(25 \%)$ of these MRSA were resistant to vancomycin.

Other studies from india ${ }^{1}$ and Pakistan. ${ }^{11}$ however did not report any vancomycin resistance. A recent multi-centre study from Greek revealed vancomycin sensitivity of $99.9 \%$, however Vancomycin Etest ${ }^{\circledR} \mathrm{MIC}_{50 / 90}$ were $1.5 / 1.5 \mathrm{mg} / \mathrm{L}$, $58.5 \%$ of isolates exhibited an MIC $>1$ and $8.7 \%$ an MIC of $2 \mathrm{mg} / \mathrm{L}$, while Vitek ${ }^{\circledR} \mathrm{MIC}_{50 / 90}$ were $1 / 1$ and $3.1 \%$ showed MIC $>1 \mathrm{mg} / \mathrm{L} .12$ They concluded that a significant percentage of contemporary S. aureus isolates from Greek patients have a vancomycin MIC ( $>1 \mathrm{mg} / \mathrm{L})$ that may compromise the clinical efficacy of the drug for the treatment of serious infections..$^{12} \mathrm{An}$ 84 samples (52\%) in the present study grew no organism.

As per the clinical details, majority of these patients were initially treated using Cefazolin and Amikacin as per the institutional protocol perhaps depicting sensitivity of these drugs. From this study, it is clear that while most of isolates from our department are still susceptible to the conventional drugs like linezolid and vancomycin, vancomycin resistance must be borne in mind. In view of convenient mode of administration and $100 \%$ sensitivity, linezolid should be the preferred treatment modality in these infections in our setup.

\section{REFERENCES}

1. Ankur Goyal1, Manish Kumar Diwakar2, Suneel Bhooshan3, et al. Prevalence and Anti-microbial Susceptibility Pattern of Methicillin-resistant Staphylococcus aureus [MRSA] isolates at a Tertiary Care Hospital in Agra, North India - A systemic annual review IOSR Journal of Dental and Medical Sciences (IOSR-JDMS Volume 11, Issue 6 (Nov.- Dec. 2013), PP 80-84.

2. Trampuz A, Widmer AF. Infections associated with orthopedic implants. Curr Opin Infect Dis 2006;19: 349-56. 
3. Patel A, Calfee RP, Plante M, et al. J Bone Joint Surg Br 2008 Nov;90(11):1401-6.

4. Enright MC, Robinson DA, Randle G, et al. The evolutionary history of methicillin-resistant Staphylococcus aureus (MRSA). Proc Natl Acad Sci USA 2002;99:7687-92.

5. Tiwari HK, Sen MR. Emergence of vancomycin resistant Staphylococcus aureus (VRSA) from a tertiary care hospital from northern part of India. BMC Infect Dis 2006;6:156.

6. Menezes GA, Harish BN, Sujatha S, et al. Emergence of vancomycin-intermediate Staphylococcus species in southern India.

J of Medical Microbiology 2008;57:911-912.

7. Assadullah S, Kakru DK, Thoker MA, et al. Emergence of low level vancomycin resistance in MRSA. Indian J Med Microbiol 2003 Jul-Sep;21(3):196-8.

8. Henry D Isenberg. Essential procedures for clinical microbiology 1998. ASM Press. Washington DC.
9. Performance standards for anti-microbial susceptibility testing; M100-S-25. Twenty fifth informational supplement 2015. Clinical and laboratory standards institute.

10. Shiddanna M Patted, Surekharani Chinagudi, Venkatesh R Soragavi, et al. The prevalence of MRSA infection in orthopaedic surgery in a Medical College Hospital: A 2year analysis. Biomedical Research 2013;24(1):33-35.

11. Kaleem F, Usman J, Hassan A, et al. Sensitivity pattern of methicillin resistant Staphylococcus aureus isolated from patients admitted in a tertiary care hospital of Pakistan. Iranian Journal of Microbiology, Volume 2, Number 3, (September 2010), 143-146.

12. Souli M, Karaiskos I, Galani L, et al. Nationwide surveillance of resistance rates of Staphylococcus aureus clinical isolates from Greek Hospitals, 2012-2013. Infect Dis (Lond). 2015 Dec 4:1-6. [Epub ahead of print]. 